\title{
Glial Cell Line-Derived Neurotrophic Factor and Chondroitinase Promote Axonal Regeneration in a Chronic Denervation Animal Model
}

Karim A. Sarhane, MD, MSc ${ }^{1,2}$. Sami H. Tuffaha, MD ${ }^{1}$ Z Zuhaib Ibrahim, MD $^{3}$. Christopher R. Cashman, MD, PhD ${ }^{4,5}$. Kellin Krick, $\mathrm{PhD}^{6,7,8} \cdot$ Russell Martin, $\mathrm{PhD}^{6,7,9}$. Justin M. Broyles, $\mathrm{MD}^{1} \cdot$ Damon S. Cooney, MD, PhD ${ }^{1}$ • W.P. Andrew Lee, MD ${ }^{1} \cdot$ Ruifa Mi, MD, PhD ${ }^{4,5} \cdot$ Hai-Quan Mao, PhD ${ }^{6,7,8,9} \cdot$ Ahmet Höke, MD, PhD ${ }^{4,5}$. Gerald Brandacher, MD $^{1}$

Published online: 30 May 2019

(C) The American Society for Experimental NeuroTherapeutics, Inc. 2019

\begin{abstract}
Functional recovery following nerve injury declines when target re-innervation is delayed. Currently, no intervention exists to improve outcomes after prolonged denervation. We explored the neuroregenerative effects of glial cell line-derived neurotrophic factor (GDNF) and chondroitinase (CDN) in a chronic denervation animal model. A fibrin-based sustained delivery method for growth factors was optimized in vitro and in vivo, and then tested in our animal model. GDNF, CDN, and GDNF+CDN were injected into the denervated stump at the time of nerve repair. Histomorphometry and retrograde labeling were used to assess axonal regeneration. The mechanisms promoting such regeneration were explored with immunofluorescence. Five weeks after repair, the GDNF+CDN group had the highest number and maturity of axons. GDNF was noted to preferentially promote axonal maturity, whereas CDN predominantly increased the number of axons. GDNF favored motor neuron regeneration, and upregulated Ki67 in Schwann cells. CDN did not favor motor versus sensory regeneration and was noted to cleave inhibitory endoneurial proteoglycans. Early measures of nerve regeneration after delayed repair are improved by activating Schwann cells and breaking down the inhibitory proteoglycans in the distal nerve segment, suggesting a role for GDNF+CDN to be translated for human nerve repairs.
\end{abstract}

Key Words Glial cell line-derived neurotrophic factor (GDNF) - chondroitinase $\cdot$ chronic denervation $\cdot$ nerve regeneration Schwann cells

Electronic supplementary material The online version of this article (https://doi.org/10.1007/s13311-019-00745-0) contains supplementary material, which is available to authorized users.

Gerald Brandacher, MD

brandacher@jhmi.edu

1 Department of Plastic and Reconstructive Surgery, Vascularized Composite Allotransplantation (VCA) Laboratory, Johns Hopkins University, Ross Research Building/Suite 749D, 720 Rutland Avenue, Baltimore, Maryland 21205, USA

2 Department of Surgery, University of Toledo College of Medicine, Toledo, Ohio, USA

3 Institute for Advanced Reconstruction, Shrewsbury, New Jersey, USA

4 Department of Neurology, Johns Hopkins University, Baltimore, Maryland, USA
5 Department of Neuroscience, Johns Hopkins University, Baltimore, Maryland, USA

6 Institute for NanoBioTechnology, Johns Hopkins University, Baltimore, Maryland, USA

7 Translational Tissue Engineering Center, Johns Hopkins University School of Medicine, Baltimore, Maryland, USA

8 Department of Biomedical Engineering, Johns Hopkins University School of Medicine, Baltimore, Maryland, USA

9 Department of Materials Science and Engineering, Whiting School of Engineering, Johns Hopkins University, Baltimore, Maryland, USA 


\section{Introduction}

Peripheral nerve injury can lead to dismal functional outcomes when regeneration is sub-optimal. Despite substantial advancements in surgical techniques and in neuropathophysiology over the past 50 years, recovery of motor and sensory functions following nerve repair remains poor [1-3]. The consequences of these outcomes (including impaired motor function, chronic pain, dysesthesia, autonomic dysfunction, disability) are oftentimes disastrous and may lead to loss of limb function. This not only results in noticeable declines in patients' quality of lives [4], but also carries dire socioeconomic consequences as most of these injuries affect the military and the working individuals [5].

Many factors determine the success of surgical repair after nerve injury. These include the type and timing of repair, the surgical technique used, the location of the lesion, as well as other elements related to the intrinsic ability of the peripheral axons to regenerate and of the distal nerve segment to support regeneration [6]. Using advanced microsurgical techniques, clinical outcomes after distal nerve injuries are usually satisfactory [2]. However, with more proximal lesions (when axons must regenerate over much longer distances) or when nerve repair is delayed, optimal functional recovery is rarely achieved [7]. This is attributed to states of chronic axotomy in which axons lose their ability to regenerate in the absence of target innervation, but more importantly, to states of chronic denervation, in which Schwann cells in the distal nerve senesce and can no longer sustain regeneration $[8,9]$. The underlying causes of this regenerative deficit are likely multiple. They include i) atrophy of Schwann cells and loss of their basal lamina in the distal nerve segment, in part due to a decrease in growth-promoting molecules such as glial cell line-derived neurotrophic factor (GDNF) and ii) increase in molecules that inhibit axonal growth in the endoneurium such as chondroitin sulfate proteoglycans (CSPGs) [10]. In this regard, therapies aiming at providing a controlled release of GDNF to the Schwann cells in the distal nerve while also degrading the proteoglycans that impede axonal growth might carry a potential in improving nerve regeneration after prolonged denervation.

In this paper, we assessed the effects of local delivery of GDNF, chondroitinase (CDN), and a combination of both in promoting axonal regeneration in a chronic denervation animal model. We utilized a preclinical nerve regeneration model, well known to recapitulate the regenerative challenges seen in human nerve repair. We first constructed a fibrin-based growth factor delivery method to provide an optimal and sustained delivery of GDNF. The release kinetics of our delivery method were fine-tuned in vitro and in vivo. We then tested it in our chronic denervation model. Finally, we investigated the underlying mechanisms through which these interventions promote axonal regeneration in chronic denervation.

\section{Methods}

\section{Fibrin Gel Construction and In Vitro Release Kinetics Study}

Fibrin gels ( $80 \mu \mathrm{l}$ total volume) were built by mixing equal parts of fibrinogen $(75-115 \mathrm{mg} / \mathrm{ml}, 40 \mu \mathrm{l})$ and thrombin $(500 \mathrm{IU} / \mathrm{ml}, 40 \mu \mathrm{l})$ from a Tisseel kit (Baxter Healthcare, Deerfield, IL). Fibrin gels were loaded with GDNF by mixing $5 \mu \mathrm{g}$ of GDNF into the thrombin solution before it was reacted with fibrinogen to form a gel.

To test the release of GDNF from fibrin, $80-\mu l$ gels with $5 \mu \mathrm{g}$ of GDNF in microcentrifuge tubes were constructed (Fisher Scientific, ON, Canada). The release time course was evaluated by incubating the fibrin gels in $1 \mathrm{ml}$ phosphatebuffered saline (PBS) containing $1 \%$ bovine serum albumin at $37^{\circ} \mathrm{C}$ under constant gentle agitation by vortex. The PBS was collected and replaced over 15 days, and samples were kept at $-20^{\circ} \mathrm{C}$. ELISAs were then performed to measure the quantity of released GDNF.

\section{Animals}

Fifty-two 5-week-old to 6-week-old female Sprague-Dawley rats (185-200 g, Charles Rivers Laboratories) were used for this study. Figure 1 illustrates the experimental design. All surgeries (including peri-operative care) followed the protocols of the Johns Hopkins University Animal Care and Use Committee according to the guidelines established by National Institutes of Health and American Association for the Accreditation of Laboratory Animal Care. All animals were kept in a central animal care facility with a 12-h light/ 12-h dark cycle and provided with food and water ad libitum.

\section{Surgical Procedure}

A chronically denervated rat tibial nerve model was used in this study [11] (Fig. 2). At the time of initial surgery, after anesthetizing the animals with inhaled isoflurane and under aseptic conditions, the right tibial nerve was transected immediately distal to the sciatic trifurcation. The distal tibial stump was reflected away from the ligated proximal stump and sutured to the nearby muscle. The transection of the tibial nerve was confirmed by measuring the compound motor action potentials (CMAPs) in the intrinsic foot muscles at the plantar surface using subdermal needle electrodes, before and after the procedure. A PowerLab signal acquisition setup (ADInstruments) was used. Stimulation was done using also subdermal needle electrodes placed near the sciatic nerve at the sciatic notch. A grounding needle electrode was placed in the tail.

Three months later, 32 of the 42 denervated animals were randomized to 4 groups (1, GDNF; $2, \mathrm{CDN} ; 3, \mathrm{GDNF}+\mathrm{CDN}$; 4 , negative control; $n=8$ per group) for the evaluation of nerve 


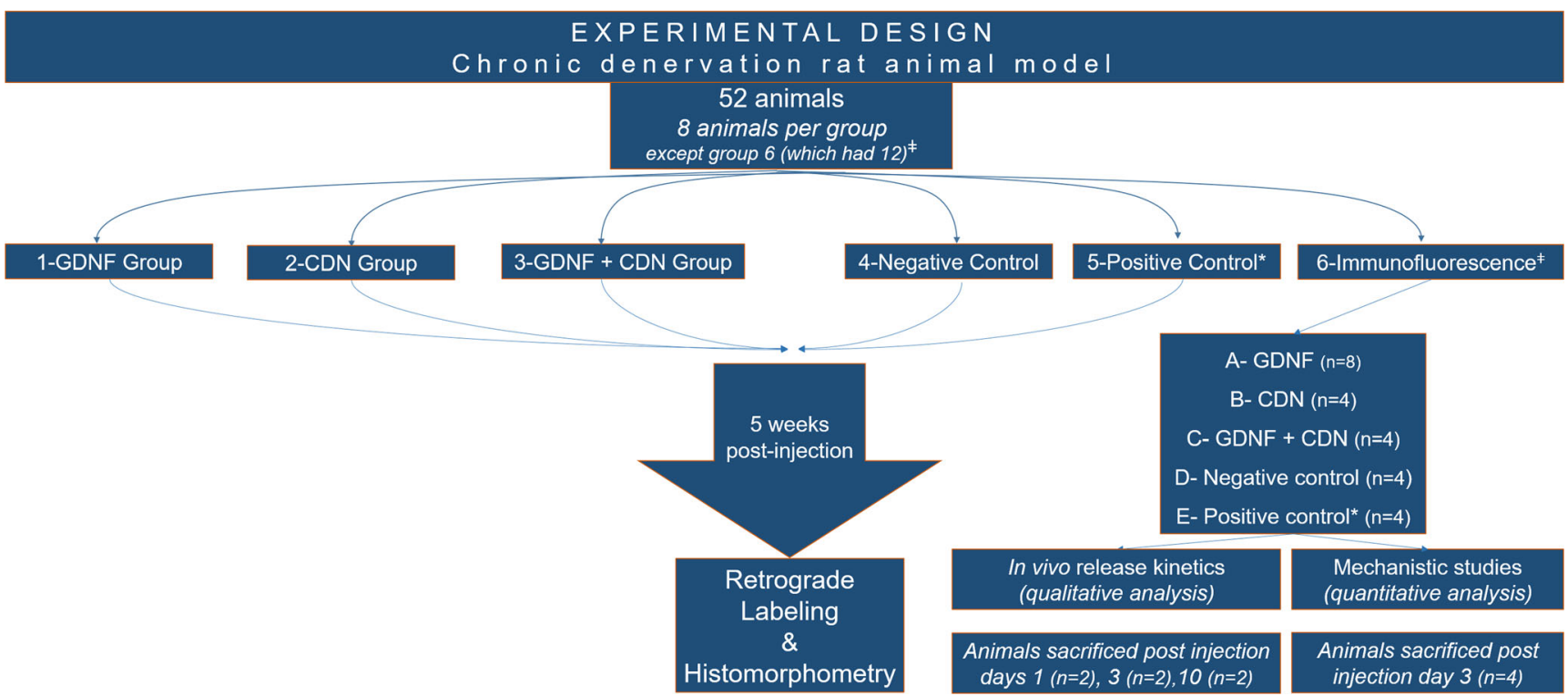

Fig. 1 Experimental design and animal groups. Alveolar click $(\ddagger)$ symbol indicates that group 6 includes 12 animals (both hindlimbs were tested, hence $n=24$ ). 10 of these 12 animals were denervated, and 2 were used as

regeneration (by histomorphometry and retrograde labeling). The remaining of the chronically denervated animals were used to test the in vivo release kinetics of GDNF and the mechanisms underlying axonal regeneration in the GDNF- and CDN-treated animals. An additional 10 animals were used as positive control, 8 for the histomorphometry/retrograde labeling experiments (group 5, positive control; $n=8$ ), and 2 for the immunofluorescent staining (subgroup E, positive control; $n=4$ ). In this positive control group, the tibial nerve was transected and cross-sutured immediately to a freshly cut peroneal nerve without the 3-month delay.

The absence of axonal growth into the distal tibial stump in the denervated animals at 3 months (before nerve transfer) positive control. Asterisk $(*)$ symbol indicates that the positive control group consists of immediate nerve transfer without denervation. GDNF $=$ glial cell line-derived neurotrophic factor; $\mathrm{CDN}=$ chondroitinase

was confirmed by measuring the CMAPs in the foot muscles. The tibial nerve was then exposed, and the connective tissue around the distal stump cleared. All groups (except for the positive control) received 5- $\mu$ l injections into the distal tibial nerve using a 33-gauge needle attached to a $10-\mu$ l Hamilton syringe. Group 1 received GDNF embedded in fibrin gel, group 2 received CDN dissolved in PBS, group 3 received a combination of both, and group 4 (negative control) received fibrin gel only; the different injections used in the experiments investigating the in vivo release kinetics of GDNF and the mechanism of regeneration in these treated animals are detailed below. The needle was advanced through the dissected stump of the distal tibial nerve until its tip was $5 \mathrm{~mm}$ distal to
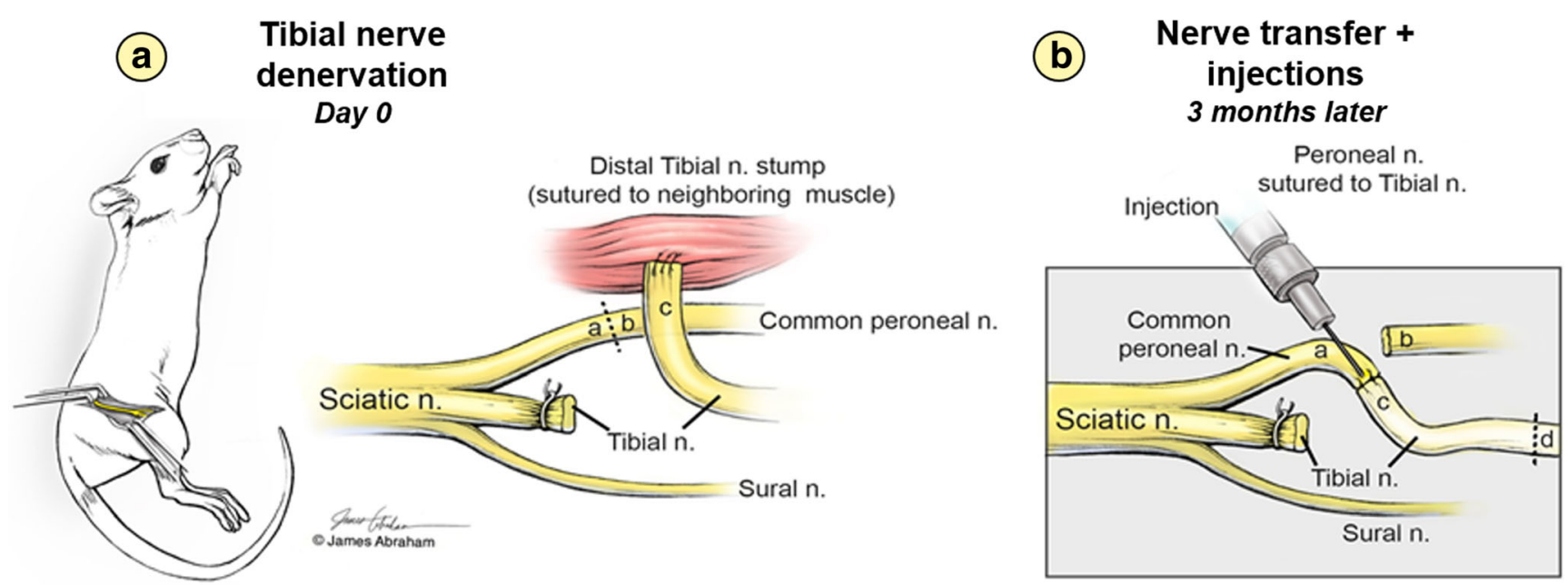

Fig. 2 Chronic denervation model and therapeutic interventions. (A) At the initial surgery, the tibial nerve is transected, and its distal stump attached to the neighboring muscle to prevent regeneration. (B) After
3 months of denervation, the tibial nerve is cross-sutured to the freshly transected common peroneal nerve and injected with the corresponding solution. 
the transection site. After the injection, the needle was kept in place for $2 \mathrm{~min}$ before it was slowly withdrawn. The peroneal nerve was then transected distal to the trifurcation, and the proximal end was cross-sutured to the chronically denervated tibial stump using 10-0 sutures. Finally, the thigh muscles were closed with 4-0 absorbable sutures and the skin with 30 non-absorbable suture. The animals were allowed to recov$\mathrm{er}$, and then returned to animal housing.

\section{Retrograde Labeling of Motor Neurons (Ventral Horn Cells) and Sensory Neurons (Dorsal Root Ganglia)}

Five weeks following nerve transfer, the incision was reopened under general anesthesia. The tibial nerve was transected $8 \mathrm{~mm}$ distal to the coaptation site. A parafilm patch was placed underneath the nerve stump to protect the underlying tissue from contact with the tracer in case of inadvertent leak during labeling. The proximal nerve stump was then introduced into a silastic tube containing 4\% Fluoro-Gold. After a 1-h incubation, the proximal tibial nerve stump was removed from the tube, rinsed with saline, and cleaned with a swab to remove any excess tracer. At the same time as labeling the proximal stump, the distal stump was harvested for histology and nerve histomorphometry. The incision was then sutured, and the animals allowed to recover.

Five days later, the animals were re-anesthetized and perfused through the left ventricle with cold saline followed by $300 \mathrm{ml}$ of $4 \%$ paraformaldehyde in $0.1 \mathrm{M}$ PBS (pH 7.40). During dissection, the sciatic nerves were traced back to the spinal cord. The dorsal root ganglia (DRG) were confirmed as being L4, L5, and L6 by counting caudally from the first dorsal roots $(\mathrm{C} 2)$ of the intact spinal cord. The spinal cord between L1 and S2 and the L4-L6 DRG were harvested. They were postfixed for $24 \mathrm{~h}$ in the same fixative at $4{ }^{\circ} \mathrm{C}$, and then transferred into $30 \%$ sucrose in $0.1 \mathrm{M}$ PBS. The L4-L6 spinal cord segments and harvested DRG were placed in TissueTek O.C.T. Compound (Saint Louis, MO), and snapfrozen in liquid nitrogen. Serial longitudinal 50- and 20- $\mu \mathrm{m}$ frozen sections from the spinal cord and DRG, respectively, were cut and mounted on coated slides. O.C.T. was removed from the air-dried sections by rinsing in PBS before the slides were finally mounted with DPX mounting media (SigmaAldrich, 06522).

\section{Microscopic Analysis and Stereological Examination}

Fluorescent-labeled neurons in the prepared spinal cord and DRG sections were identified using a fluorescent microscope, Zeiss Axio Imager-2 (Carl Zeiss Microimaging LLC, Thornwood, NY) equipped with the corresponding singleband pass filters (Semrock, Rochester, NY). Both transverse plane and rostro-caudal views were obtained.
For an unbiased estimation of their number, labeled neuron populations in spinal cord section and every fifth DRG section for each animal were sampled using the optical dissector method [12]. This method has previously been validated for frozen tissue [13]. To compensate for the problem of uneven distribution of labeled neurons within a spinal cord and DRG tissue, a set sampling path was followed from a random starting point of each section sampled. A neuron was counted only if its nucleus could be clearly identified. Counts were expressed as mean \pm standard deviation (SD).

\section{Histology and Morphometric Evaluation of Nerves}

To quantify the number of regenerating axons and assess their maturity, nerve tissue taken $8 \mathrm{~mm}$ distal to the coaptation site was studied. After harvest, it was fixed in $2 \%$ glutaraldehyde, then postfixed in $1 \%$ osmium tetroxide, dehydrated in ethanol, and finally embedded in Araldite 502 (Polysciences, Inc., Warrington, PA). Thin $(0.6-\mu \mathrm{m})$ sections were obtained and stained with $1 \%$ toluidine blue for examination under light microscopy. The slides were qualitatively evaluated for overall nerve architecture and quality of regenerated fibers. At $\times$ 1000 overall magnification (using Olympus BX51WI), the entire nerve cross section was captured and evaluated with image analysis software (Image J, NIH) using customdesigned plugins, based on a previous methodology [14]. Morphometric measurements obtained from the entire cross section included 1$)$ average axon number $(N) ; 2)$ average fiber diameter $(\mu \mathrm{m})$; 3 ) fiber diameter distribution; and 4) average myelin sheath thickness $(\mu \mathrm{m})$. A minimum of 300 fibers per nerve were randomly sampled and measured. All values of morphometric measures were shown as mean $\pm \mathrm{SD}$.

\section{In Vivo Release Kinetics and Mechanistic Studies}

Co-immunofluorescence studies were performed in the 12 animals of group 6 (using both hindlimbs, i.e., $n=24$ ) to investigate the in vivo release kinetics of GDNF from fibrin gel, as well as the mechanisms through which GDNF and CDN promote axonal regeneration in a chronically denervated environment. There were 5 subgroups: A, GDNF (4 animals, $n=8)$; B, CDN (2 animals, $n=4)$; C, GDNF+CDN (2 animals, $n=4)$; D, negative control (2 animals, $n=4)$; and $\mathrm{E}$, positive control ( 2 animals, $n=4$ ) (Fig. 1). After 3 months of denervation (subgroups A-D), the distal tibial nerve stump was injected with the factor(s) being tested (or with empty gel), and then cross-sutured to a freshly transected common peroneal nerve, as outlined above. Animals were sacrificed at different time points depending on the experimental assay.

For the studies evaluating the mechanisms through which GDNF and CDN contributed to axonal regeneration (2 animals from each group, or $n=4$ ), rats were sacrificed 3 days 
after nerve transfer. Schwann cell activation and CSPG degradation were assessed in all 5 subgroups.

Schwann cell activation was defined by the expression of Ki67 on S100 cells [15]. Slides were co-stained with antiS100/anti-Ki67 antibodies. For quantitative analysis, $\sim 200$ cells that stained positive for S100 were identified from 6 to 8 random $0.1 \mathrm{~mm}^{2}$ microscope fields. Of those cells, the ones that co-stained for Ki67 were counted, and the percentage of Ki67 expression among S100 cells was computed and compared among the 5 subgroups.

CSPG degradation was defined by the presence of the cleaved chondroitin 4-sulfate (C4S) epitope [16]. Slides were co-stained with anti-chondroitin 4-sulfate/anti-TUJ1 antibodies. For quantitative analysis, the fluorescence of $\mathrm{Cy} 5$ was measured (in pixels) in 4 random $0.1 \mathrm{~mm}^{2}$ microscope fields and compared among the 5 subgroups.

For the in vivo release kinetics of GDNF from fibrin gel (involving 3 animals from subgroup A, or $n=6$ ), there were 3 endpoints: day $1(n=2)$, day $3(n=2)$, and day $10(n=2)$ after nerve transfer. To note, slides from 1 of the 2 GDNF animals that was sacrificed at day 3 for the mechanistic studies were also used for the day 3 in vivo release assessment. Qualitative evaluation of Alexa594 fluorescence (in pixels) was performed to determine the presence of GDNF on days 1, 3, and 10 post-injection.

Whole animal transcardiac perfusion fixation technique was performed as described above, and the common peroneal/tibial nerves were harvested. They were postfixed for $24 \mathrm{~h}$ using the same fixative at $4{ }^{\circ} \mathrm{C}$, and then transferred to $30 \%$ sucrose in $0.1 \mathrm{M}$ PBS. They were then embedded into O.C.T. medium and snap-frozen in liquid nitrogen. Sections $(10 \mu \mathrm{m})$ were cut using a cryostat and mounted on coated slides. A list of the antibodies that were used in these experiments is presented in Table 1 . Briefly, the sections were initially treated with $0.2 \%$ Triton X-100 for 10 min at room temperature (permeabilization step). After rinsing in PBS, the sections were covered with $10 \%$ normal goat serum and incubated for $60 \mathrm{~min}$. The slides were then washed in PBS and incubated overnight with the primary antibodies (diluted in PBS containing 5\% normal goat serum) in a humidified chamber at $4{ }^{\circ} \mathrm{C}$. Sixteen hours later, sections were washed in PBS and incubated for $1 \mathrm{~h}$ with the corresponding secondary antibodies in a humidified chamber at room temperature, and finally mounted using ProLong Gold Antifade Mountant containing DAPI (Life Technologies). Negative control slides were included in each of these experiments, using the exact staining steps but omitting the primary antibody. The nerves were imaged under fluorescent filtration with the use of a Zeiss Axio Imager-2. All images were obtained with matched exposure settings and in a blinded fashion.

\section{Statistics}

Statistical analysis was performed using the Kruskal-Wallis one-way analysis of variance by ranks. Provided significant differences were detected, the Dwass-Steel-CritchlowFligner post hoc analysis method was applied for multiple pairwise comparisons. A $p$ value $<0.05$ was considered significant. SPSS Statistics version 23 (IBM, Armonk, NY) was used.

\section{Results}

\section{In Vitro and In Vivo Release of GDNF from Fibrin Gels}

In vitro, the dynamic release of GDNF from fibrin gel during the polymerization into $\mathrm{PBS}(\mathrm{pH} 7.4$, containing $0.1 \%$ bovine serum albumin) was followed for 4 days at $37^{\circ} \mathrm{C}$. Figure $3 \mathrm{~A}$ demonstrates this release. The data are normalized to the recovered GDNF (free GDNF, $4.5 \pm 0.1 \mu \mathrm{g}$ ). A statistically equivalent total amount of GDNF was released from the GDNF fibrin gel. No large initial burst of GDNF release from the fibrin gels was observed, probably due to the high concentration of fibrinogen within the fibrin gels $(\sim 50 \mathrm{mg} / \mathrm{ml})$. The system delivered GDNF at levels $\geq 0.1 \mu \mathrm{g}$ /day for at least 4 days.

In vivo, the repair site was found to be completely enveloped by GDNF-containing gel 1 day post-injection. GDNF remained in place for at least 3 days and was visibly degraded by day 10 (Fig. 3B).

\section{Morphometric Measures of Nerve Regeneration}

Five weeks following nerve transfer, cross sections were harvested $8 \mathrm{~mm}$ distal to the coaptation site for histological and histomorphometric analysis (Fig. 4A) to assess the extent of nerve regeneration.

\section{Number of myelinated axons (Fig. 4B)}

There was a statistically significant difference in the number of myelinated axons between the different groups, $\chi^{2}(2)=$ $34.53, p=0.001$, with a mean rank of 36.50 for positive control, 25.5 for GDNF+CDN, 22.50 for CDN, 13.50 for GDNF, and 4.50 for negative control. Pairwise comparisons revealed that the positive control group had the highest number of regenerated axons. Next came both the GDNF+CDN and CDN groups (which were statistically similar), then the GDNF group, and finally the negative control group.

\section{Myelin sheath thickness and fiber diameter (Fig. 4B)}

There was a statistically significant difference in the myelin sheath thickness between the different groups, $\chi^{2}(2)=$ $32.75, p=0.001$, with a mean rank of 35.81 for positive control, 27.50 for GDNF+CDN, 21.06 for GDNF, 12.50 for $\mathrm{CDN}$, and 5.63 for negative control. Pairwise 
Table 1 Immunofluorescence antibodies used for the in vivo release kinetics and mechanistic studies

\begin{tabular}{lllll}
\hline Co-staining combinations & Source & Catalog no./clone & Dilution \\
\hline Primary & Mouse anti-chondroitin 4-sulfate & Millipore & MAB2030 & $1: 100$ \\
Secondary & Cy5 goat anti-mouse & Jackson labs & $115-175-166$ & $1: 600$ \\
Primary & Rabbit anti-TUJ1 & Covance & MRB-435P & $1: 2000$ \\
Secondary & Fluorescein goat anti-rabbit & Vector labs & FI-1000 & $1: 800$ \\
Primary & Mouse anti-S100 & Abcam & ab11179/ab14849 & $1: 500 / 1: 100$ \\
Secondary & Alexa488 donkey anti-mouse & Jackson labs & $715-545-150$ & $1: 200$ \\
Primary & Rabbit anti-Ki67 & Thermo Scientific & RM-9106-S0 & $1: 400$ \\
Secondary & Alexa594 goat anti-rabbit & Jackson labs & $711-585-152$ & $1: 500$ \\
Primary & Rabbit anti-GDNF & PeproTech & $500-P 81$ & $1: 500$ \\
Secondary & Alexa594 goat anti-rabbit & Jackson labs & $711-585-152$ & $1: 500$ \\
Primary & Mouse anti-TUJ1 & Promega & G7121 & $1: 1000$ \\
Secondary & Alexa488 donkey anti-mouse & Jackson labs & $715-545-150$ & $1: 200$ \\
\hline
\end{tabular}

comparisons revealed that the positive control group had the thickest myelin sheath. Then, came both GDNF+CDN and GDNF (which were statistically similar). CDN and negative control followed. Although $\mathrm{CDN}$ had a greater myelin thickness than negative control, the difference did not reach a customary level of significance $(p=0.06)$.

As for fiber diameter, there was a statistically significant difference between the different groups, $\chi^{2}(2)=31.66, p=$
0.001 , with a mean rank of 36.13 for positive control, 24.81 for GDNF+CDN, 23.94 for GDNF, 12.81 for CDN, and 4.81 for negative control. Pairwise comparisons revealed that the positive control group had the highest fiber diameter. Next came both GDNF+CDN and GDNF (which were statistically similar). CDN followed, and negative control was last (here, the difference between $\mathrm{CDN}$ and negative control was significant).

a

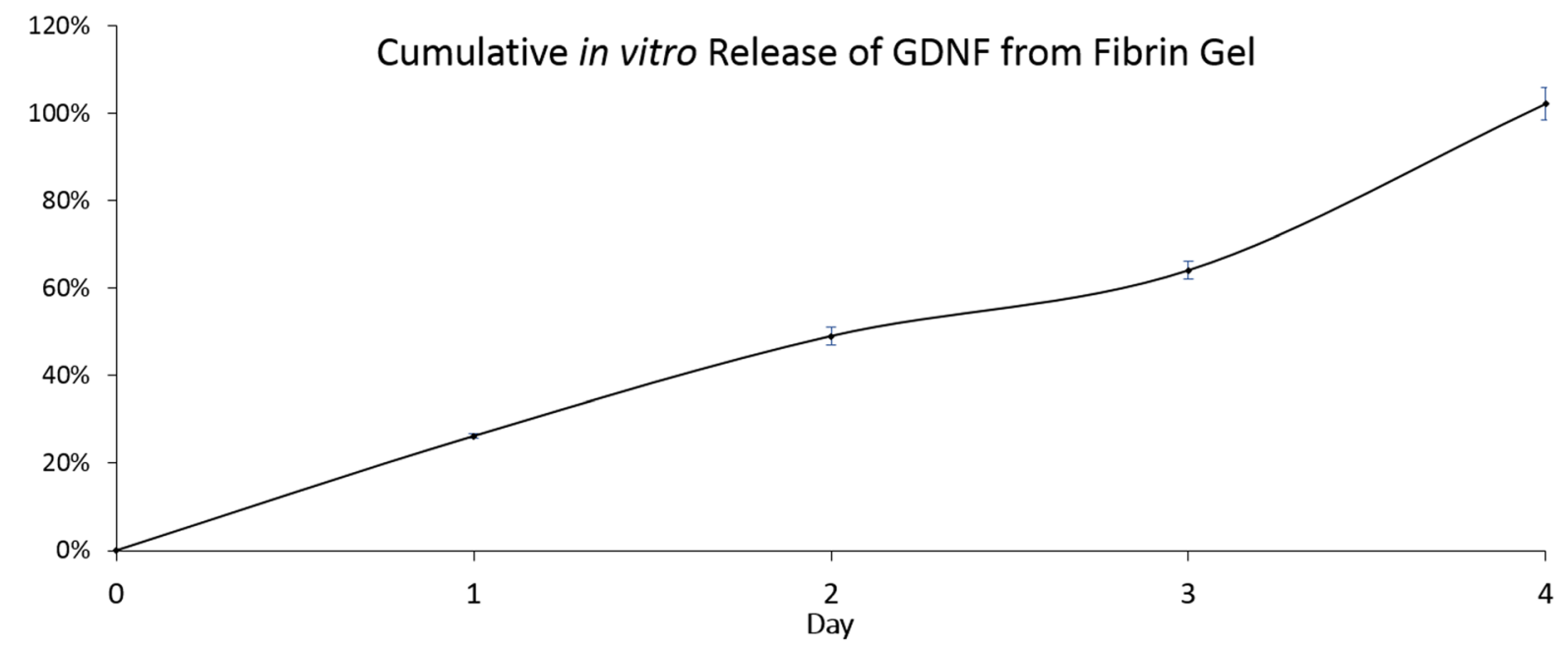

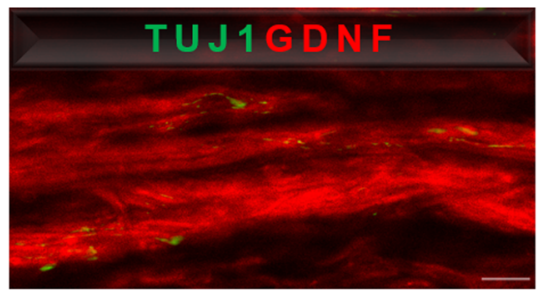

Day 1

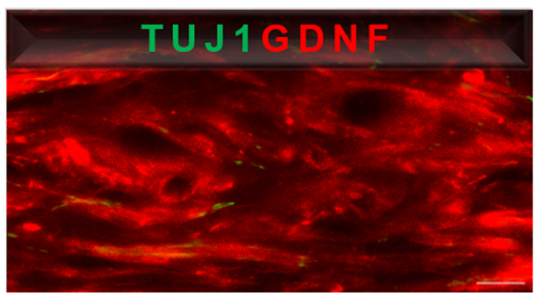

Day 3

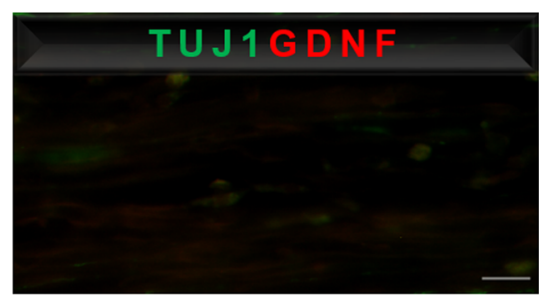

Day 10
Fig. 3 In vitro (A) and in vivo (B) release kinetics of GDNF from fibrin gels. (A) In vitro release was followed for 4 days at $37^{\circ} \mathrm{C}$. No large initial burst of GDNF release was noted. Release levels reached $\geq 0.1 \mu \mathrm{g} /$ day for at least 4 days. (B) In vivo release was performed in a chronic denervation model. Immunofluorescent longitudinal sections of the nerve distal to the repair site at days 1,3 , and 10 following injection of GDNF-loaded fibrin gel are shown. GDNF was present on days 1 and 3, and absent on day 10 . Scale bars, $20 \mu \mathrm{m}$. Error bars represent standard deviations 
a

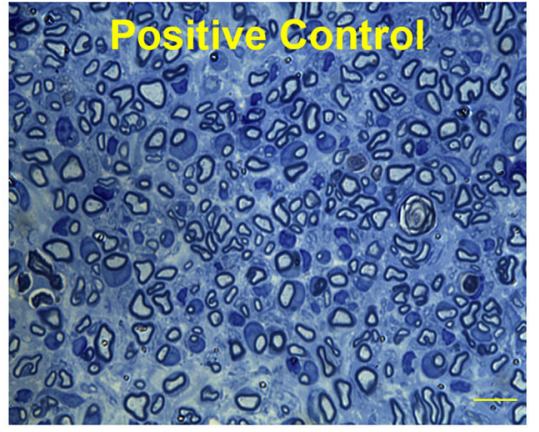

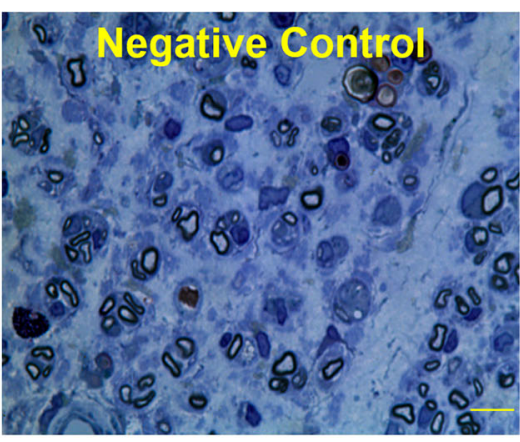

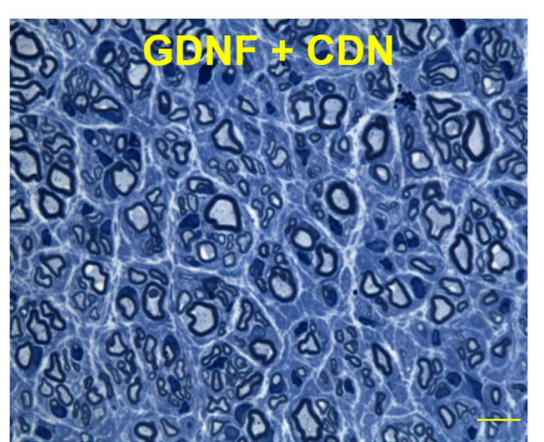

b
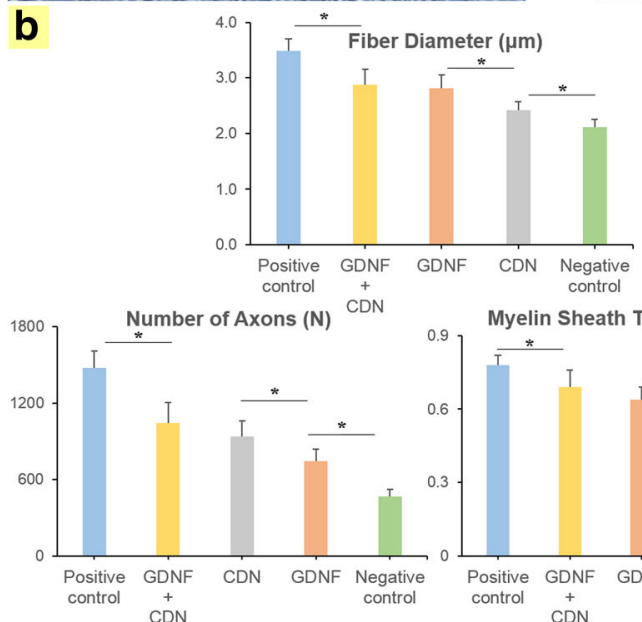

Myelin Sheath Thickness $(\mu \mathrm{m})$

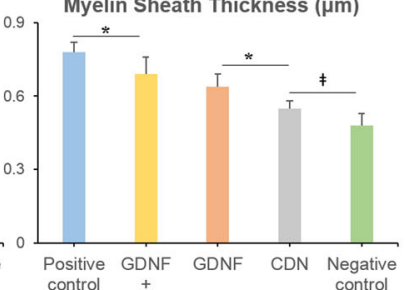

$\stackrel{+}{\operatorname{CDN}}$

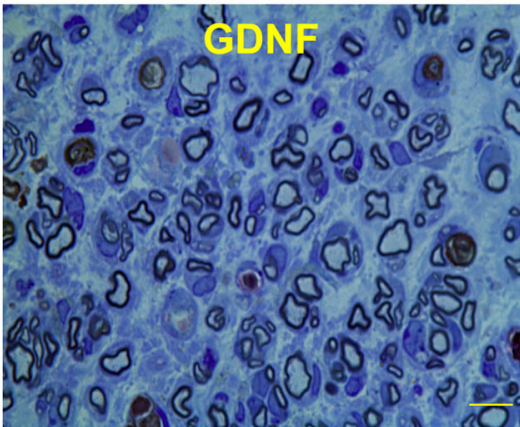

C $\square<1 \mu \mathrm{m}$ (smallest)

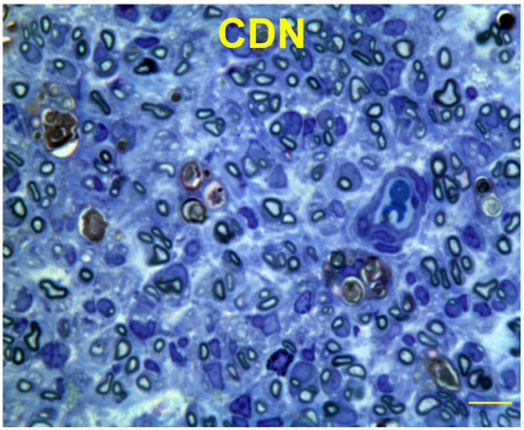

口1-2 $\mu \mathrm{m}$ (small)

$\square>4 \mu \mathrm{m}$ (largest)

$\square 2-3 \mu \mathrm{m}$ (medium)

$45 \%$ ] $3-4 \mu \mathrm{m}$ (large) $*$

Fig. 4 Histomorphometric assessment of nerve regeneration. The panel (A) shows representative toluidine blue cross sections of regenerated nerves taken from each group 5 weeks following nerve transfer. A minimum of 300 fibers per nerve were randomly sampled and measured. Panel (B) displays a quantification analysis of nerve morphometric parameters. Cross sections were analyzed for number of

\section{Fiber diameter distribution (Fig. 4C)}

Subgroup analysis was performed to examine the distribution of fiber diameter in the 5 groups (positive control, GDNF+ CDN, GDNF, CDN, negative control). Fiber diameter subgroups were defined as smallest $(<1 \mu \mathrm{m})$, small $(1-2 \mu \mathrm{m})$, medium $(2-3 \mu \mathrm{m})$, large $(3-4 \mu \mathrm{m})$, and largest $(>4 \mu \mathrm{m})$ diameter.

All 5 groups showed a statistically significant difference in the proportion of fibers of different sizes. $\chi^{2}(2)$ values were 33.14 (positive control), $34.52(\mathrm{GDNF}+\mathrm{CDN}), 35.17$

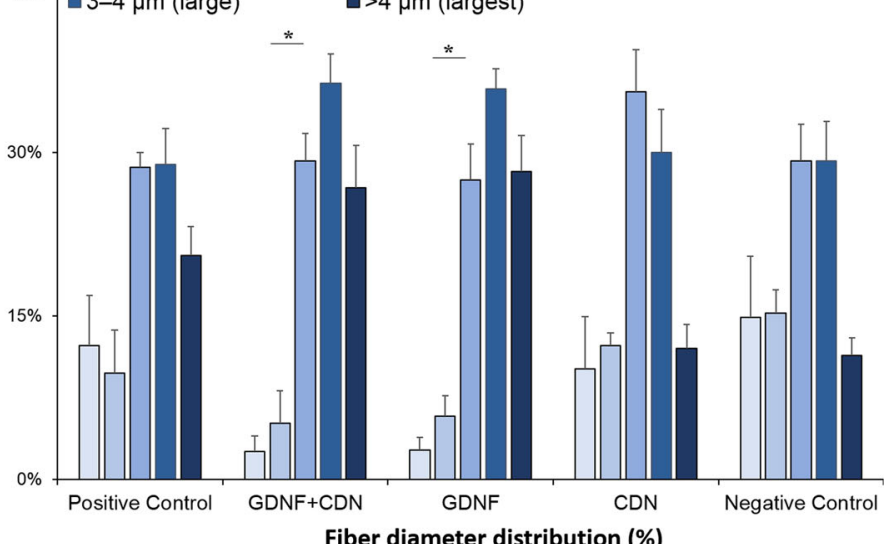

axons, myelin sheath thickness, and fiber diameter. Panel $(\mathbf{C})$ presents a subgroup analysis of fiber diameters. Statistical comparison was performed using the Kruskal-Wallis test, and pairwise comparison using the Dwass-Steel-Critchlow-Fligner method. Mean \pm SD are shown; error bars represent standard deviations. $* p<0.05$; alveolar click ( $\ddagger$ symbol indicates approaching significance. Scale bars, $10 \mu \mathrm{m}$

(GDNF), 29.54 (CDN), and 31.15 (negative control); all $p$ values were less than 0.001 . Pairwise comparisons within each group revealed the following:

The distribution pattern of fiber diameter is similar in the untreated groups (positive and negative control). In these untreated groups, the proportion of medium and large fibers (as well as that of the smallest and small fibers) is similar. In the GDNF-treated groups, however (both GDNF+CDN and GDNF groups), the proportion of large fibers is significantly higher than that of medium fibers. This pattern is not observed in the $\mathrm{CDN}$-treated group, in which the proportion of medium 
and large fibers is still similar. This observation suggests that GDNF, in the setting of chronic denervation, potentiates the regeneration of large mature fibers.

On the other hand, in all treated groups $(\mathrm{GDNF}+\mathrm{CDN}$, GDNF, and CDN), the overall proportion of medium and large fibers is higher than that of negative control. This shows that the higher number of axons noted in the treated groups consists principally of mature fibers.

It is worth noting here that, within the " $>4 \mu \mathrm{m}$ (largest)" category, the majority of the fibers in the positive control group $(66.49 \%$ ) have a diameter of $7-8 \mu \mathrm{m}$, whereas the majority of the fibers in the other groups have a diameter of 4 $4.5 \mu \mathrm{m}(98.62 \%$ in GDNF+CDN; $98.23 \%$ in GDNF; $99 \%$ in $\mathrm{CDN}$ and $100 \%$ in the negative control group). This explains why the positive control group has the highest average of fiber diameter (Supplemental Figure 1).

\section{Retrograde Labeling of Neurons Following Nerve Transfer}

To quantify the percentage of motor and sensory neurons that regenerated their axons in response to the injected growth factors, Fluoro-Gold retrograde dye was applied to regenerated axons $8 \mathrm{~mm}$ distally from the coaptation site 5 weeks after nerve transfer. Labeled cells were characterized by red-yellow fluorescence. In the majority of cases, identification of neuronal nuclei was possible due to the bigger size of neuronal than glial cell nuclei and typical distribution of glial cells around the neurons. However, difficulties were encountered in performing unbiased identification of neuronal nuclei in areas with a high density of labeled cells. The histograms in Fig. 5 (bottom panel) display the raw motor and sensory neuron counts along with the proportion of neurons that regenerated their axons in each group (assuming positive control achieved $100 \%$ regeneration).

\section{Motor Neurons}

There was a statistically significant difference between the number of motor neurons that regenerated their axons among the different groups $\left(\chi^{2}(2)=34.44, p=0.001\right)$, with a mean rank of 36.50 for positive control, 26.38 for GDNF+CDN, 22.63 for GDNF, 10.13 for CDN, and 6.88 for negative control. Pairwise comparisons revealed significant differences between positive control and GDNF+CDN, between GDNF and $\mathrm{CDN}$, and between GDNF and negative control. GDNF+ $\mathrm{CDN}$ was similar to GDNF. CDN and negative control were also similar.

\section{Sensory Neurons}

There was a statistically significant difference between the number of sensory neurons that regenerated their axons by different groups $\left(\chi^{2}(2)=20.24, p=0.001\right)$, with a mean rank of 36.50 for positive control, 20.69 for GDNF+CDN, 16.25 for GDNF, 14.13 for CDN, and 14.94 for negative control. Pairwise comparisons revealed a significant difference between positive control and GDNF+CDN. All other groups were similar.

\section{Mechanisms Underlying GDNF and CDNs Induced Axonal Regeneration}

The injection of GDNF-loaded fibrin gels in chronically denervated tibial segments was found to stimulate Schwann cells to upregulate the proliferation marker Ki67. The proportion of S100 cells expressing Ki67 increased from $12.94 \% \pm 0.97$ in the negative control group to $28.62 \% \pm 1.71$ in the GDNF group $(p<0.05)$, and to $27.57 \% \pm 1.71$ in the GDNF+CDN group $(p<0.05)$. This suggests enhanced activation of Schwann cells as a mechanism that supported and sustained axonal growth in chronic denervation (Fig. 5, top panel). To note, the proportion of $\mathrm{S} 100$ cells expressing Ki67 following $\mathrm{CDN}$ injection $(11.82 \% \pm 1.05)$ was similar to that of negative control. This implies that CDN injection had no effect on Schwann cell activation (Supplemental Figure 2).

$\mathrm{CDN}$ injection was found to result in positive staining for the cleaved chondroitin sulfate epitope $\mathrm{C} 4 \mathrm{~S}$. The fluorescence of C4S increased from $99.68 \pm 8.45$ pixels in the negative control group to $349.88 \pm 18.40$ pixels in the CDN-treated group $(p<0.01)$, and to $353.26 \pm 20.58$ pixels in the GDNF+CDN group $(p<0.01)$. This confirms digestion of chondroitin sulfate side chains by chondroitinase, and subsequent loss of the growth inhibitory endoneurial molecules. This reduction in growth inhibitory compounds may be a mechanism for improved axonal growth in chronic denervation (Fig. 5, top panel). To note, C4S staining was not noted neither in the GDNF-treated group, $99.73 \pm 9.83$ pixels, nor in the positive control group, $97.34 \pm 8.21$ pixels (Supplemental Figure 3). This implies that GDNF treatment has no effect on CSPG degradation; these are digested following CDN injection.

\section{Discussion}

Peripheral nerve injury continues to pose unique challenges to both clinicians and patients. Whenever the injury occurs distally and is followed by immediate repair, axonal regeneration is still possible as the integrity of the Schwann cells' basal lamina is maintained. These cells provide the axonal cone with growth-promoting substrates and shield it from the growth inhibitory extracellular matrix components (namely CSPGs) [17].

However, in the clinically relevant situation of delayed nerve repair, the Schwann tubes are not intact anymore as they 


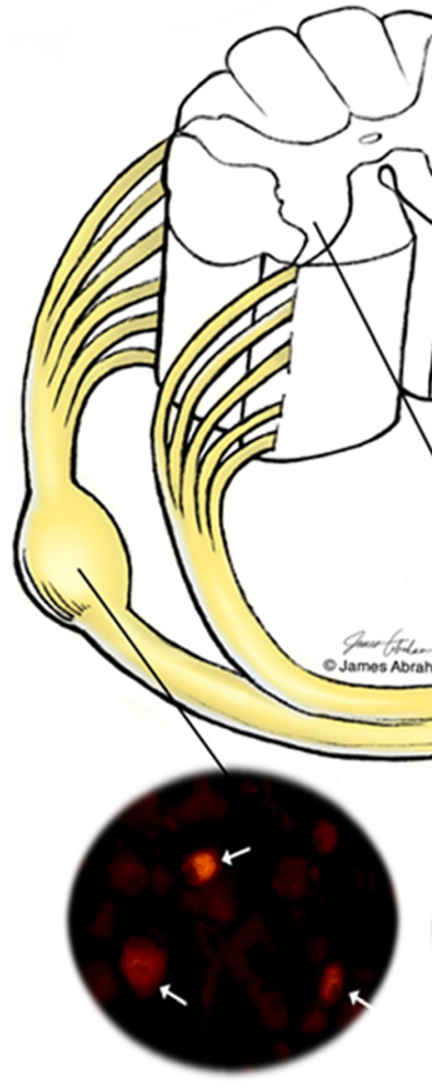

1. Sensory Neurons

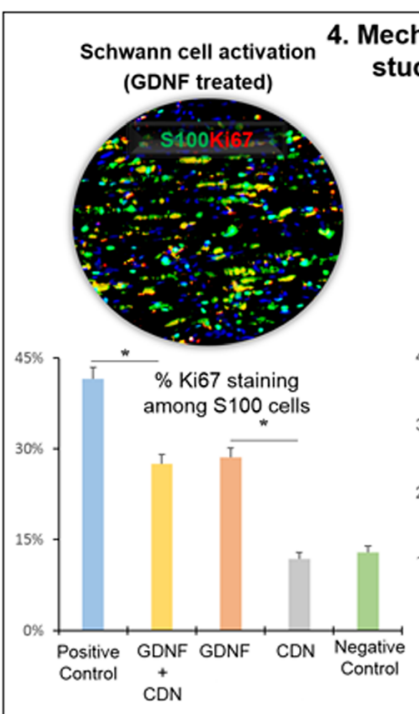

4. Mechanistic studies

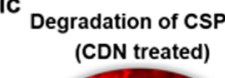
(CDN treated)
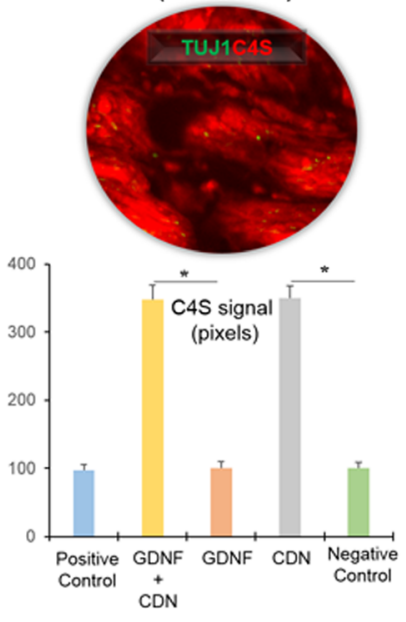

$\stackrel{+}{\mathrm{CDN}}$

1)

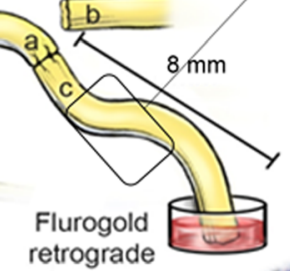

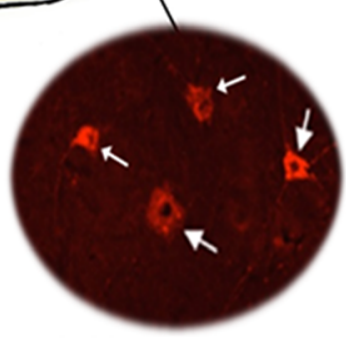

2. Motor Neurons

labeling

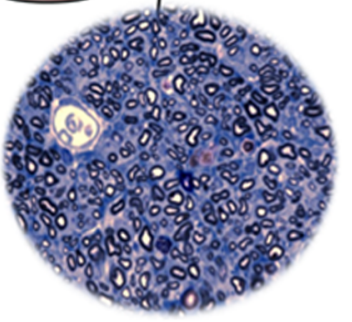

3. Histomorphometry

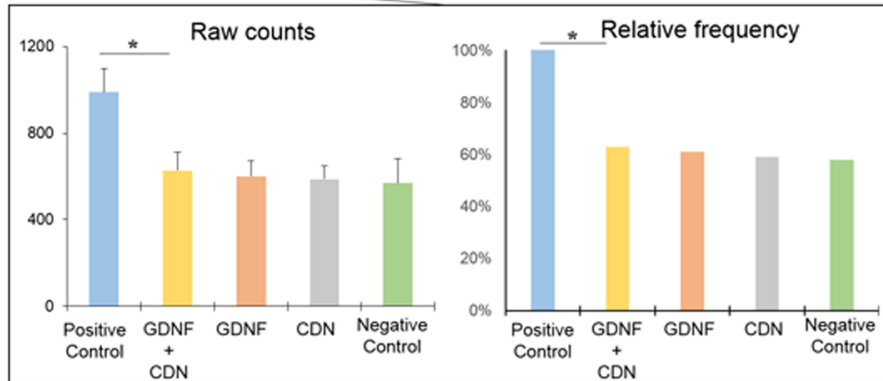

Fig. 5 Five weeks following nerve transfer, retrograde labeling of neurons regenerating their axons was performed $8 \mathrm{~mm}$ distal to the coaptation site. Sensory neurons in the dorsal root ganglia $(1 ; 20-\mu \mathrm{m}$ sections, every fifth section counted) and ventral horn cells in the spinal cord $(2 ; 50-\mu \mathrm{m}$ sections, all sections counted) were counted to assess motor and sensory neuron regeneration, respectively. The distal stump (3) was sent for nerve histomorphometry. In addition (4), immunofluorescent staining was performed to understand the mechanisms through which GDNF and CDN promote axonal growth. The injection of GDNF increased the percentage of S100 cells co-expressing Ki67 almost twofold

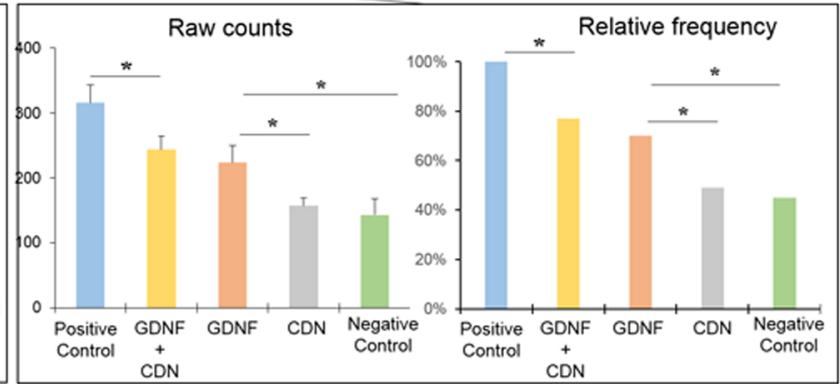

(from $12.94 \% \pm 0.97$ in the negative control to $28.62 \% \pm 1.71$ in the GDNF group, and to $27.57 \% \pm 1.54$ in the GDNF+CDN group). The injection of CDN resulted in the degradation of CSPGs as evidenced by an increase in the fluorescence of $\mathrm{C} 4 \mathrm{~S}$ (from $99.68 \pm 8.45$ pixels in the negative control to $349.88 \pm 18.40$ pixels in the $\mathrm{CDN}$ group and to $353.26 \pm 20.58$ pixels in the GDNF+CDN group). Statistical comparison was performed using the Kruskal-Wallis test, and pairwise comparison using the Dwass-Steel-Critchlow-Fligner method. Mean \pm SD are shown; error bars represent standard deviations. ${ }^{*} p<0.05$

molecules of the extracellular matrix. There is also less growth-promoting molecules in this milieu. Such an shrink by $80-90 \%$ in the first 3 months $[18,19]$. The regenerating axons are thus exposed to the growth-inhibiting 
environment does not sustain effective nerve regeneration and may result in severe functional disabilities [2, 10].

In this regard, a modality that reactivates Schwann cells in the denervated segment to stimulate their secretion of neurotrophic factors might enhance the capacity for axonal regeneration following delayed nerve repair. To achieve optimal outcomes, this modality must also degrade the inhibitory molecules within the denervated segment to further augment axonal elongation.

In this paper, we developed a fibrin-based delivery method that releases a sustained and constant amount of GDNF. GDNF is one of the most prominent neurotrophic factors playing a role in the survival of motor neurons and their regeneration [20-23]. The effects of this modality on axonal regeneration were tested in a chronic denervation animal model. Along with GDNF, we also investigated the impact of $\mathrm{CDN}$ therapy on axonal growth. $\mathrm{CDN}$ is a glycosidase that deactivates CSPGs, which are known to be major inhibitory regulators of axonal regeneration after nerve injury [24, 25]. In our study, we chose a chronic denervation rat animal model, as this model accounts for the prolonged periods that are required for human nerve regeneration. It thus replicates similar changes in the human denervated nerve segments, reproducing the challenges to human nerve regeneration [26]. This makes our model favorable for testing translational therapeutic advances.

To our knowledge, this study is the first to examine the therapeutic potential of GDNF, CDN, and a combination of both in the setting of chronic denervation. In an acute denervation model, GDNF expression is known to upregulate in the distal stump $48 \mathrm{~h}$ after injury. This is to promote neurite outgrowth. However, as the duration of denervation is increased, GDNF expression is lost. This is mainly due to Schwann cell senescence and their inability to secrete GDNF [27]. Such changes in GDNF levels may explain the poor axonal regeneration seen in chronic denervation. Thus, we hypothesized that treating the distal stump with a modality that releases a sustained amount of GDNF will activate these senescent Schwann cells and stimulate them to secrete the necessary growth-promoting molecules that sustain axonal growth. Our data supported this hypothesis. We found that the GDNF-treated groups exhibited a higher number and maturity of regenerated axons. This was accompanied by a nearly twofold increase in the expression of Ki67 on Schwann cells suggesting that their activation might have mediated the positive effects of GDNF.

There have been mixed reports with regard to whether a continuous supply of GDNF is required to elicit a significant neurotrophic response [28, 29], or if similar results can be obtained after a single dose [30, 31]. The consensus from these studies is that a single dose is enough to improve axonal regeneration, but a more prolonged release (achieved mainly with mini-osmotic pumps) leads to a greater benefit. Implanted osmotic pumps and infusion catheters, however, whereas suitable for experimental analysis, are unlikely to be adopted for clinical use in human nerve repair. In our study, we decided on a compromise to use a fibrin-based system for delivery of GDNF over 4 days, as this method carries a greater translational potential in nerve repair (as compared with implanted catheters).

Axonal regeneration is characterized by a complex interaction of growth-promoting and inhibitory molecules. In order to achieve optimal regenerative outcomes, we chose to supplement our GDNF treatment with another therapy that works through a different mechanism (degradation of growth inhibitory molecules, CSPGs). Although the presence and role of CSPGs in the CNS have been substantially studied [32], their impact on the regeneration of the acutely injured peripheral nerve is the subject of a considerable amount of research. Following acute peripheral nerve transection, neurite outgrowth inhibitory molecules (such as CSPGs) are upregulated within the distal stump $[33,34]$. The growth inhibitory influence of CSPGs becomes detrimental as neural tissue attempts to regenerate [35]. Using the enzyme CDN, the inhibitory properties of CSPGs can be overcome. This was demonstrated both in vitro [36, 37] and in vivo [38-41] (in acute injury models). In these animal studies, a single injection of CDN into the distal stump at the time of nerve repair resulted in the digestion of CSPGs and a marked elevation of axonal growth. CDN therapy was however not investigated in a chronically denervated nerve stump. Because it is known that the gene expression pattern in delayed repair of rat sciatic nerves (as compared with immediate repair) is characterized by a noticeable increase in the expression of phosphacan and, to a lesser extent, versican (phosphacan and versican being CSPGs) [42], we hypothesized that CDN therapy would also promote axonal growth in the setting of chronic denervation. Our results supported this hypothesis. CDN therapy resulted in a significant increase in the number of regenerated axons. These effects were suggested to be mediated by the digestion of the growth inhibitory CSPGs, as demonstrated by the significant increase in their degradation product (C4S).

Although our model involved the deposition of a biomaterial loaded with GDNF directly into the denervated distal stump, it is worth noting that there are other nerve repair techniques that involve different modalities for local delivery of neurotrophic proteins. One of these is the use of synthetic conduits loaded with growth factors. This modality has been largely used in acute injury models, and rarely in chronic denervation. Barras et al. used it in chronically denervated rat facial nerves. In their study, they combined a nerve graft with a GDNF-releasing synthetic conduit (made from nonresorbable ethylene vinyl acetate) to repair the facial nerve after a 7-month period of delay. The GDNF-releasing channel was placed between the graft and the denervated distal stump. This modality resulted in an increase in the number and maturation of nerve fibers (as compared with nerve graft alone, 
and to nerve graft with an empty channel) [43]. These results underline the critical importance of Schwann cell activation in the denervated distal stump to support axonal regeneration. Notwithstanding the possible differences between facial and sciatic nerve regeneration, we speculate that a useful synthetic conduit for a chronic denervation model would also address the other challenges seen in chronic denervation. Besides distal stump Schwann cell senescence, these also include the accumulation of growth inhibitory molecules. Thus, the conduit would provide the necessary factors (e.g., GDNF and $\mathrm{CDN}$ ) to the denervated distal stump to overcome these challenges. In addition, refinements can be introduced in the fabrication of the conduit itself (fiber pore and size, etc.) to modulate the inflammatory response at the repair site towards a regenerative phenotype, as we have previously shown in an acute injury model [44]. Such bioactive synthetic scaffolds loaded with growth factors might hold promising avenues in chronic denervation models.

Our data suggest that GDNF is mainly contributing to fiber maturity (by enhancing fiber diameter and myelin sheath thickness), and that $\mathrm{CDN}$ is primarily promoting the number of regenerated axons (as evidenced by an increased axonal count). When used together, both modalities worked synergistically to enhance the number of regenerated axons and their maturity (i.e., myelin sheath thickness and diameter). Our hypothesis is that the GDNF-activated Schwann cells produced regeneration-promoting factors (like nerve growth factor (NGF), brain-derived growth factor (BDNF), GDNF [45-47]), and aligned to regular structures (Bands of Büngner) which stimulated axonal regeneration. Equally important, $\mathrm{CDN}$ shielded these regenerating axons from the endoneurial growth inhibitory molecules, CSPGs, and allowed them to reach the endoneurial tubes. Altogether, GDNF and CDN helped to establish a regenerationpermissive environment for the growing axons. Our findings show that this combination carries the potential to be translated for use in human nerve repair. Moreover, they also shed light on some of the basic changes that occur in the distal portion of nerves after a period of denervation, and that hinder regeneration.

It is important to mention that one of the limitations of our study is the lack of functional analysis. Our 5-week endpoint was not long enough for the regenerating axons to reach their target muscle; hence, we were unable to assess the sciatic function index and could not perform nerve conduction studies. Based on our data, we would anticipate a higher compound muscle action potential amplitude (i.e., increased number of axons connected to muscle fibers) in the CDN-treated groups, and a shorter latency (i.e., higher number of mature fibers reaching the muscle target) in the GDNF-treated groups. A longer-term endpoint (14-16 weeks) that allows a comprehensive assessment of functional recovery is essential to further support our conclusions.

\section{Conclusion}

In summary, early measures of nerve regeneration after delayed nerve repair are best improved by simultaneously targeting axonal growth (using GDNF) and degrading inhibitory molecules in the distal stump (using CDN).

Acknowledgments The authors would like to thank Mr. James Abraham, $\mathrm{MA}$, for designing the illustrations; and Baohan $\mathrm{Pan}, \mathrm{MD}, \mathrm{PhD}$, for his technical assistance. The authors also acknowledge partial support to this work by the Maryland Stem Cell Research Fund (2012- MSCRF-008300 G.B.), and by Dr. Miriam and Sheldon G. Adelson Medical Research Foundation (A.H.).

Required Author Forms Disclosure forms provided by the authors are available with the online version of this article.

\section{Compliance with Ethical Standards}

All surgeries (including peri-operative care) followed the protocols of the Johns Hopkins University Animal Care and Use Committee according to the guidelines established by National Institutes of Health and American Association for the Accreditation of Laboratory Animal Care.

\section{References}

1. Benga A, Zor F, Korkmaz A, et al. The neurochemistry of peripheral nerve regeneration. Indian J Plast Surg [Internet] 2017 [cited 2018 May 13];50:5-15. Available from: http://www.ncbi.nlm.nih. gov/pubmed/28615804.

2. Scheib J, Höke A. Advances in peripheral nerve regeneration. Nat Rev Neurol [Internet] 2013 [cited 2014 Sep 25];9:668-676. Available from: http://www.ncbi.nlm.nih.gov/pubmed/24217518.

3. Faroni A, Mobasseri SA, Kingham PJ, et al. Peripheral nerve regeneration: Experimental strategies and future perspectives. Adv Drug Deliv Rev [Internet] 2015 [cited 2018 May 21];82-83:160 167. Available from: https://www.sciencedirect.com/science/ article/pii/S0169409X14002737.

4. Robinson LR. Traumatic injury to peripheral nerves. Muscle Nerve [Internet] 2000 [cited 2015 Sep 14];23:863-873. Available from: http://www.ncbi.nlm.nih.gov/pubmed/10842261.

5. de Putter CE, Selles RW, Polinder S, et al. Economic Impact of Hand and Wrist Injuries: Health-Care Costs and Productivity Costs in a Population-Based Study. J Bone Jt Surg Am [Internet] 2012 [cited 2018 May 8];94:e56-1-7. Available from: http://www. ncbi.nlm.nih.gov/pubmed/22552678.

6. Höke A. A (heat) shock to the system promotes peripheral nerve regeneration. J Clin Invest [Internet] 2011 [cited 2015 Sep 16];121: 4231-4234. Available from: http://www.pubmedcentral.nih.gov/ articlerender.fcgi? artid $=3204849 \&$ tool=pmcentrez\&rendertype $=$ abstract.

7. Brushart T. Nerve Repair. New York: Oxford University Press; 2011.

8. Fu SY, Gordon T. Contributing factors to poor functional recovery after delayed nerve repair: prolonged axotomy. J Neurosci [Internet] 1995 [cited 2015 Sep 16];15:3876-3885. Available from: http:// www.ncbi.nlm.nih.gov/pubmed/7751952.

9. Fu SY, Gordon T. Contributing factors to poor functional recovery after delayed nerve repair: prolonged denervation. J Neurosci [Internet] 1995 [cited 2012 Dec 29]; 15:3886-3895. Available from: http://www.ncbi.nlm.nih.gov/pubmed/7751953. 
10. Höke A. Proteoglycans in axonal regeneration. Exp Neurol [Internet] 2005 [cited 2015 Sep 16];195:273-277. Available from: http://www.sciencedirect.com/science/article/pii/ S0014488605002268.

11. Höke A, Gordon T, Zochodne DW, et al. A Decline in Glial CellLine-Derived Neurotrophic Factor Expression Is Associated with Impaired Regeneration after Long-Term Schwann Cell Denervation. Exp Neurol [Internet] 2002 [cited 2018 May 5];173: 77-85. Available from: http://www.ncbi.nlm.nih.gov/pubmed/ 11771940.

12. Gundersen HJ, Bagger P, Bendtsen TF, et al. The new stereological tools: disector, fractionator, nucleator and point sampled intercepts and their use in pathological research and diagnosis. APMIS. 1988;96:857-881.

13. Messina A, Sangster CLC, Morrison WA, et al. Requirements for obtaining unbiased estimates of neuronal numbers in frozen sections. J Neurosci Methods. 2000;97:133-137.

14. Hunter DA, Moradzadeh A, Whitlock EL, et al. Binary imaging analysis for comprehensive quantitative histomorphometry of peripheral nerve. J Neurosci Methods [Internet]. 2007 [cited 2012 Nov 8];166:116-124. Available from: http://www.pubmedcentral. nih.gov/articlerender.fcgi? artid $=2587177 \&$ tool $=$ pmcentrez\&rendertype $=$ abstract.

15. Benito C, Davis CM, Gomez-Sanchez JA, et al. STAT3 Controls the Long-Term Survival and Phenotype of Repair Schwann Cells during Nerve Regeneration. J Neurosci [Internet] 2017 [cited 2019 Apr 19];37:4255-4269. Available from: http://www.ncbi.nlm.nih. gov/pubmed/28320842.

16. Tuffaha S, Quigley M, Ng T, et al. The effect of chondroitinase on nerve regeneration following composite tissue allotransplantation. J Hand Surg Am [Internet] 2011 [cited 2013 Sep 7];36:1447-1452. Available from: http://www.ncbi.nlm.nih.gov/pubmed/21788107.

17. Zochodne DW. The challenges and beauty of peripheral nerve regrowth. J Peripher Nerv Syst [Internet] 2012 [cited 2018 May 13];17:1-18. Available from: http://www.ncbi.nlm.nih.gov/ pubmed/22462663.

18. Sunderland S, Bradley KC. Denervation atrophy of the distal stump of a severed nerve. J Comp Neurol [Internet] 1950 [cited 2019 Feb 22];93:401-409. Available from: http://www.ncbi.nlm.nih. gov/pubmed/14803568.

19. Sunderland S, Bradley KC. Endoneurial tube shrinkage in the distal segment of a severed nerve. J Comp Neurol [Internet] 1950 [cited 2019 Feb 22];93:411-420. Available from: http://www.ncbi.nlm. nih.gov/pubmed/14803569.

20. Bohn MC. Motoneurons crave glial cell line-derived neurotrophic factor. Exp Neurol [Internet] 2004 [cited 2015 Oct 25];190:263275. Available from: http://www.ncbi.nlm.nih.gov/pubmed/ 15530868.

21. Brunet N, Tarabal O, Portero-Otín M, et al. Survival and death of mature avian motoneurons in organotypic slice culture: trophic requirements for survival and different types of degeneration. J Comp Neurol [Internet] 2007 [cited 2015 Oct 25];501:669-690. Available from: http://www.ncbi.nlm.nih.gov/pubmed/17299760.

22. Pajenda G, Hercher D, Márton G, et al. Spatiotemporally limited BDNF and GDNF overexpression rescues motoneurons destined to die and induces elongative axon growth. Exp Neurol [Internet] 2014 [cited 2015 Oct 25];261:367-376. Available from: http:// www.ncbi.nlm.nih.gov/pubmed/24873730.

23. Vyas A, Li Z, Aspalter M, et al. An in vitro model of adult mammalian nerve repair. Exp Neurol [Internet] 2010 [cited 2015 Oct 25];223:112-118. Available from: http://www.pubmedcentral. nih.gov/articlerender.fcgi?artid $=2849894 \&$ tool $=$ pmcentrez\&rendertype $=$ abstract.

24. Muir D, Engvall E, Varon S, et al. Schwannoma cell-derived inhibitor of the neurite-promoting activity of laminin. J Cell Biol [Internet] 1989 [cited 2015 Oct 25];109:2353-2362. Available from: http://www.pubmedcentral.nih.gov/articlerender.fcgi?artid= 2115873\&tool=pmcentrez\&rendertype $=$ abstract.

25. Zuo J, Neubauer D, Dyess K, et al. Degradation of Chondroitin Sulfate Proteoglycan Enhances the Neurite-Promoting Potential of Spinal Cord Tissue. Exp Neurol [Internet] 1998 [cited 2015 Oct 12];154:654-662. Available from: http://www.ncbi.nlm.nih. gov/pubmed/9878200.

26. Höke A. Mechanisms of Disease: what factors limit the success of peripheral nerve regeneration in humans? Nat Clin Pract Neurol [Internet] 2006 [cited 2019 Feb 22];2:448-454. Available from: http://www.ncbi.nlm.nih.gov/pubmed/16932603.

27. Höke A, Gordon T, Zochodne DW, et al. A Decline in Glial CellLine-Derived Neurotrophic Factor Expression Is Associated with Impaired Regeneration after Long-Term Schwann Cell Denervation. Exp Neurol [Internet] 2002 [cited 2019 Feb 22];173: 77-85. Available from: http://www.ncbi.nlm.nih.gov/pubmed/ 11771940

28. Vejsada R, Tseng JL, Lindsay RM, et al. Synergistic but transient rescue effects of BDNF and GDNF on axotomized neonatal motoneurons. Neuroscience [Internet] 1998 [cited 2019 Apr 18];84:129139. Available from: http://www.ncbi.nlm.nih.gov/pubmed/ 9522368.

29. Boyd JG, Gordon T. Glial cell line-derived neurotrophic factor and brain-derived neurotrophic factor sustain the axonal regeneration of chronically axotomized motoneurons in vivo. Exp Neurol [Internet]. 2003 [cited 2019 Apr 18];183:610-619. Available from: http://www.ncbi.nlm.nih.gov/pubmed/14552902.

30. Chai $\mathrm{H}, \mathrm{Wu} \mathrm{W}$, So KF, et al. Long-term effects of a single dose of brain-derived neurotrophic factor on motoneuron survival following spinal root avulsion in the adult rat. Neurosci Lett [Internet]. 1999 [cited 2019 Apr 17];274:147-150. Available from: http:// www.ncbi.nlm.nih.gov/pubmed/10548411.

31. Koliatsos VE, Clatterbuck RE, Winslow JW, et al. Evidence that brain-derived neurotrophic factor is a trophic factor for motor neurons in vivo. Neuron [Internet]. 1993 [cited 2019 Apr 17];10:359367. Available from: http://www.ncbi.nlm.nih.gov/pubmed/ 8080464.

32. Galtrey CM, Fawcett JW. The role of chondroitin sulfate proteoglycans in regeneration and plasticity in the central nervous system. Brain Res Rev [Internet] 2007 [cited 2019 Feb 22];54:1-18. Available from: http://www.ncbi.nlm.nih.gov/pubmed/17222456.

33. Zuo J, Neubauer D, Graham J, et al. Regeneration of axons after nerve transection repair is enhanced by degradation of chondroitin sulfate proteoglycan. Exp Neurol [Internet] 2002 [cited 2019 Feb 22];176:221-228. Available from: http://www.ncbi.nlm.nih. gov/pubmed/12093099.

34. Zuo J, Hernandez YJ, Muir D. Chondroitin sulfate proteoglycan with neurite-inhibiting activity is up-regulated following peripheral nerve injury. J Neurobiol [Internet]. 1998 [cited 2019 Feb 22];34: 41-54. Available from: http://www.ncbi.nlm.nih.gov/pubmed/ 9469617.

35. Gause II TM, Sivak WN, Marra KG. The Role of Chondroitinase as an Adjuvant to Peripheral Nerve Repair. Cells Tissues Organs [Internet] 2015 [cited 2019 Feb 22];200:59-68. Available from: http://www.ncbi.nlm.nih.gov/pubmed/25766067.

36. Vahidi B, Park JW, Kim HJ, et al. Microfluidic-based strip assay for testing the effects of various surface-bound inhibitors in spinal cord injury. J Neurosci Methods [Internet]. 2008 [cited 2019 Feb 22];170:188-196. Available from: http://www.ncbi.nlm.nih. gov/pubmed/18314199.

37. Grimpe B, Pressman Y, Bunge MB, et al. The role of proteoglycans in Schwann cell/astrocyte interactions and in regeneration failure at PNS/CNS interfaces. Mol Cell Neurosci [Internet]. 2005 [cited 2019 Feb 22];28:18-29. Available from: http://www.ncbi.nlm.nih. gov/pubmed/15607938. 
38. Graham JB, Neubauer D, Xue Q-S, et al. Chondroitinase applied to peripheral nerve repair averts retrograde axonal regeneration. Exp Neurol [Internet] 2007 [cited 2015 Oct 25];203:185-195. Available from: http://www.pubmedcentral.nih.gov/articlerender.fcgi?artid= $1851897 \&$ tool $=$ pmcentrez\&rendertype $=$ abstract.

39. Neubauer D, Graham JB, Muir D. Chondroitinase treatment increases the effective length of acellular nerve grafts. Exp Neurol [Internet] 2007 [cited 2015 Oct 25];207:163-170. Available from: http://www.pubmedcentral.nih.gov/articlerender.fcgi?artid= $2956445 \&$ tool $=$ pmcentrez\&rendertype $=$ abstract

40. Zuo J, Neubauer D, Graham J, et al. Regeneration of axons after nerve transection repair is enhanced by degradation of chondroitin sulfate proteoglycan. Exp Neurol [Internet] 2002 [cited 2015 Oct 25];176:221-228. Available from: http://www.ncbi.nlm.nih. gov/pubmed/12093099.

41. Cheng C-H, Lin C-T, Lee M-J, et al. Local Delivery of High-Dose Chondroitinase $\mathrm{ABC}$ in the Sub-Acute Stage Promotes Axonal Outgrowth and Functional Recovery after Complete Spinal Cord Transection. Di Giovanni S, editor. PLoS One [Internet]. 2015 [cited 2018 May 8];10:e0138705. Available from: http://dx.plos.org/ 10.1371/journal.pone.0138705.

42. Jonsson S, Wiberg R, McGrath AM, et al. Effect of Delayed Peripheral Nerve Repair on Nerve Regeneration, Schwann Cell Function and Target Muscle Recovery. Gillingwater TH, editor. PLoS One [Internet]. 2013 [cited 2019 Feb 22];8:e56484. Available from: http://www.ncbi.nlm.nih.gov/pubmed/23409189.

43. Barras FM, Kuntzer T, Zurn AD, et al. Local delivery of glial cell line-derived neurotrophic factor improves facial nerve regeneration after late repair. Laryngoscope [Internet] 2009 [cited 2019 Apr 18];119:846-855. Available from: http://doi.wiley.com/10. 1002/lary.20169.
44. Sarhane KA, Ibrahim Z, Martin R, et al. Macroporous nanofiber wraps promote axonal regeneration and functional recovery in nerve repair by limiting fibrosis. Acta Biomater [Internet] 2019 [cited 2019 Apr 18];88:332-345. Available from: http://www. ncbi.nlm.nih.gov/pubmed/30807875.

45. Huang L, Quan X, Liu Z, et al. c-Jun gene-modified Schwann cells: upregulating multiple neurotrophic factors and promoting neurite outgrowth. Tissue Eng Part A [Internet] 2015 [cited 2015 Oct 25];21:1409-1421. Available from: http://www.ncbi.nlm.nih. gov/pubmed/25588149.

46. Funakoshi H, Frisén J, Barbany G, et al. Differential expression of mRNAs for neurotrophins and their receptors after axotomy of the sciatic nerve. J Cell Biol [Internet] 1993 [cited 2013 Sep 3];123: 455-465. Available from: http://www.pubmedcentral.nih.gov/ articlerender.fcgi? artid=2119843\&tool=pmcentrez\&rendertype $=$ abstract.

47. Xu P, Rosen KM, Hedstrom K, et al. Nerve injury induces glial cell line-derived neurotrophic factor (GDNF) expression in Schwann cells through purinergic signaling and the PKC-PKD pathway. Glia [Internet] 2013 [cited 2015 Oct 25];61:1029-1040. Available from: http://www.pubmedcentral.nih.gov/articlerender.fcgi?artid= 4165612\&tool=pmcentrez\&rendertype $=$ abstract.

Publisher's Note Springer Nature remains neutral with regard to jurisdictional claims in published maps and institutional affiliations. 